\title{
BILANGAN STRONG RAINBOW CONNECTION UNTUK GRAF RODA DAN GRAF KUBIK
}

\author{
WITRI YULIANI \\ Program Studi Magister Matematika, \\ Fakultas Matematika dan Ilmu Pengetahuan Alam, Universitas Andalas \\ Limau Manis Padang, Sumatera Barat, Indonesia, \\ email : witriyuliani.wy@gmail.com
}

\begin{abstract}
Abstrak. Misalkan $G=(V(G), E(G))$ adalah suatu graf terhubung tak trivial. Definisikan suatu pewarnaan $c: E(G) \rightarrow\{1,2, \cdots, k\}, k \in N$, dimana dua sisi yang bertetangga boleh berwarna sama. Suatu lintasan $u-v$ path $P$ di $G$ dinamakan rainbow path jika tidak terdapat dua sisi di $P$ yang berwarna sama. Graf $G$ disebut rainbow connected jika setiap dua titik yang berbeda di $G$ dihubungkan oleh rainbow path. Pewarnaan sisi yang menyebabkan $G$ bersifat rainbow connected dikatakan rainbow coloring. Bilangan Rainbow connection dari graf terhubung $G$, ditulis $r c(G)$, didefinisikan sebagai banyaknya warna minimal yang diperlukan untuk membuat graf $G$ bersifat rainbow connected. Misalkan $c$ adalah rainbow coloring dari graf terhubung $G$. Untuk dua titik $u$ dan $v$ di $G$, rainbow $u-v$ geodesic pada $G$ adalah rainbow $u-v$ path yang panjangnya $d(u, v)$ dimana $d(u, v)$ adalah jarak antara $u$ dan $v$ (panjang $u-v$ path terpendek di $G$. Graf $G$ dikatakan strongly rainbow connected jika $G$ memiliki suatu rainbow $u-v$ geodesic untuk setiap dua titik $u$ dan $v$ di $G$. Minimum $k$ yang terdapat pada pewarnaan $c$ sedemikian sehingga $G$ adalah strongly rainbow connected dikatakan bilangan strong rainbow connection, $\operatorname{src}(G)$, di $G$. Pada paper ini akan dikaji tentang bilangan strong rainbow connection untuk graf Roda dan graf Kubik.
\end{abstract}

Kata Kunci: Bilangan Strong Rainbow Connection, graf Roda, graf Kubik

\section{Pendahuluan}

Konsep rainbow connection suatu graf pertama kali diperkenalkan oleh Chartrand, Johns, McKeon dan Zhang [3] pada tahun 2006. Misalkan $G=(V(G), E(G))$ adalah suatu graf terhubung tak trivial. Definisikan suatu pewarnaan $c: E(G) \rightarrow$ $\{1,2, \cdots, k\}, k \in N$, dimana dua sisi yang bertetangga boleh berwarna sama. Suatu lintasan $u-v$ path $P$ di $G$ dinamakan rainbow path jika tidak terdapat dua sisi di $P$ yang berwarna sama. Graf $G$ disebut rainbow connected jika setiap dua titik yang berbeda di $G$ dihubungkan oleh rainbow path.

Pewarnaaan sisi yang menyebabkan $G$ bersifat rainbow connected dikatakan rainbow coloring. Jelas jika $G$ adalah rainbow connected, maka $G$ terhubung. Sebaliknya, setiap graf terhubung memiliki pewarnaan sisi trivial sehingga $G$ bersifat rainbow connected, yaitu setiap sisi diwarnai dengan warna berbeda. Bilangan Rainbow connection dari graf terhubung $G$, ditulis $r c(G)$, didefinisikan sebagai banyaknya warna minimal yang diperlukan untuk membuat graf $G$ bersifat rainbow connected. Suatu rainbow coloring yang menggunakan sebanyak $r c(G)$ warna dikatakan minimum rainbow coloring. 
Misalkan $c$ adalah rainbow coloring dari graf terhubung $G$. Untuk dua titik $u$ dan $v$ di $G$, rainbow $u-v$ geodesic pada $G$ adalah rainbow $u-v$ path yang panjangnya $d(u, v)$ dimana $d(u, v)$ adalah jarak antara $u$ dan $v$ (panjang $u-v$ path terpendek di $(G)$. Graf $G$ dikatakan strongly rainbow connected jika $G$ memiliki suatu rainbow $u-v$ geodesic untuk setiap dua titik $u$ dan $v$ di $G$. Dalam kasus ini, pewarnaan $c$ dikatakan strong rainbow coloring di $G$. Minimum $k$ yang terdapat pada pewarnaan $c: E(G) \rightarrow\{1,2, \cdots, k\}$ sedemikian sehingga $G$ adalah strongly rainbow connected dikatakan bilangan strong rainbow connection atau strong rainbow connection number, $\operatorname{src}(G)$, di $G$. Suatu strong rainbow coloring di $G$ yang menggunakan $\operatorname{src}(G)$ warna dikatakan minimum strong rainbow coloring di $G$. Jadi, $r c(G) \leq \operatorname{src}(G)$ untuk setiap graf terhubung di $G$ [3]. Selanjutnya, jika $G$ adalah graf terhubung tak trivial dengan ukuran $m$ dan $\operatorname{diam}(G)=\max \{d(u, v) \mid u, v \in V(G)\}$, maka

$$
\operatorname{diam}(G) \leq \operatorname{rc}(G) \leq \operatorname{src}(G) \leq m .
$$

Pada paper ini akan dikaji tentang bilangan strong rainbow connection untuk graf Roda dan graf Kubik.

\section{Beberapa Konsep dalam Rainbow Connection}

Berikut disajikan kembali proposisi yang membahas tentang graf $G$ dengan ukuran $m$ yang mempunyai nilai $\operatorname{rc}(G)$ dan $\operatorname{src}(G) 1,2$ dan $m$.

Proposisi 2.1. [3] Misalkan G suatu graf terhubung tak trivial berukuran m. Maka berlaku

(1) $\operatorname{rc}(G)=\operatorname{src}(G)=1$ jika dan hanya jika $G$ suatu graf lengkap,

(2) $\operatorname{rc}(G)=2$ jika dan hanya jika $\operatorname{src}(G)=2$,

(3) $r c(G)=\operatorname{src}(G)=m$ jika dan hanya jika $G$ suatu graf pohon.

\section{Bukti.}

(1) Jika pada graf lengkap $G$ diberikan 1 warna untuk tiap sisi-sisinya, maka untuk setiap dua titik $u$ dan $v$ di $G$ terdapat rainbow 1-coloring yang juga merupakan $u-v$ geodesic. Jadi $G$ merupakan rainbow 1-coloring dan strong rainbow 1coloring sehingga $\operatorname{rc}(G)=\operatorname{src}(G)=1$. Jika $r c(G)=\operatorname{scr}(G)=1$ tidak ada dua titik yang tidak bertetangga maka haruslah $G$ merupakan graf lengkap.

(2) Jika $r c(G)=2$, ini berarti $G$ memiliki suatu rainbow 2-coloring yang mengakibatkan setiap dua titik yang tidak bertetangga dihubungkan oleh suatu rainbow path dengan panjang 2, maka haruslah $\operatorname{scr}(G) \geq 2$. Karena lintasan tersebut merupakan geodesic, jadi tidak mungkin $\operatorname{scr}(G)>2$ maka $\operatorname{src}(G)=2$. Sebaliknya, asumsikan $\operatorname{src}(G)=2$. berdasarkan (1) haruslah $\operatorname{cr}(G) \leq 2$. karena $G$ bukan merupakan graf lengkap, sehingga $\operatorname{rc}(G)=2$.

(3) Andaikan $G$ bukan graf pohon. Maka $G$ memiliki suatu lingkaran $C$ : $v_{1}, v_{2}, \cdots, v_{k}, v_{1}$ dimana $k \geq 3$. Maka $(m-1)-$ coloring terhadap sisi-sisi $G$ yang memberikan 1 untuk sisi $v_{1} v_{2}$ dan $v_{2} v_{3}$, dan memberikan $(m-2)$ buah warna berbeda dari himpunan warna $\{2,3, \cdots, m-1\}$ untuk $m-2$ sisi tesisa di $G$ adalah rainbow coloring. Jadi, $r c(G) \leq m-1$. Selanjutnya misalkan $G$ 
adalah graf pohon dengan ukuran $m$. Asumsikan bahwa $r c(G) \leq m-1$. Misalkan $c$ adalah suatu minimum rainbow coloring di $G$. Maka terdapat sisi $e$ dan $f$ sehingga $c(e)=c(f)$. Asumsikan tanpa mengurangi perumuman, bahwa $e=u v$ dan $f=x y$, dan $G$ memiliki suatu $u-y$ path $u, v, \cdots, x, y$. Maka tidak terdapat rainbow $u-y$ path di $G$, kontradiksi dengan $G$ mempunyai rainbow coloring. Jadi, haruslah $G$ adalah graf pohon berukuran $m$.

Proposisi 2.2. [3] Misalkan $C_{n}$ adalah graf lingkaran dengan banyak titik $n$, dimana $n \geq 4 \operatorname{maka} r c\left(C_{n}\right)=\operatorname{src}\left(C_{n}\right)=\left\lceil\frac{n}{2}\right\rceil$.

Bukti. Misalkan terdapat graf lingkaran $C_{n}$, dimana

$$
\begin{aligned}
& V\left(C_{n}\right)=\left\{v_{1}, v_{2}, \cdots, v_{n}, v_{1}\right\}, \\
& E\left(C_{n}\right)=\left\{v_{i} v_{i+1} \mid 1 \leq i \leq n\right\} \cup\left\{v_{1} v_{n}\right\} .
\end{aligned}
$$

Pandang dua kasus berikut.

Kasus 1. $n$ genap.

Misalkan $n=2 k$ untuk bilangan bulat $k \geq 2$ maka jelas bahwa

$$
\operatorname{src}\left(C_{n}\right) \geq \operatorname{rc}\left(C_{n}\right) \geq \operatorname{diam}\left(C_{n}\right)=k .
$$

Selanjutnya, konstruksikan pewarnaan sisi $c$ dari $C_{n}$ sebagai berikut.

$$
c\left(e_{i}\right)=\left\{\begin{array}{l}
i, \quad \text { untuk } 1 \leq i \leq k \\
i-k, \text { untuk } k+1 \leq i \leq n .
\end{array}\right.
$$

Berdasarkan pertidaksamaan 1.1, berlaku $r c\left(C_{n}\right) \leq \operatorname{src}\left(C_{n}\right) \leq k$, sehingga $r c\left(C_{n}\right)=\operatorname{src}\left(C_{n}\right)=k$.

Kasus 2. $n$ ganjil.

Misalkan $n=2 k+1$ untuk bilangan bulat $k \geq 2$. Konstruksikan pewarnaan sisi $f$ dari $C_{n}$ dengan

$$
f\left(e_{i}\right)= \begin{cases}i, & \text { untuk } 1 \leq i \leq k+1 \\ i-k-1, & \text { untuk } k+2 \leq i \leq n .\end{cases}
$$

Karena $f$ adalah strong rainbow $(k+1)$-coloring dari $C_{n}$ maka $r c\left(C_{n}\right) \leq \operatorname{src}\left(C_{n}\right) \leq$ $k+1$. Karena $r c\left(C_{n}\right) \geq \operatorname{diam}\left(C_{n}\right)=k$ maka $\operatorname{rc}\left(C_{n}\right)=k$ atau $r c\left(C_{n}\right)=k+1$. Selanjutnya, klaim bahwa $r c\left(C_{n}\right)=k+1$. Andaikan $r c\left(C_{n}\right)=k$. Misalkan $f^{\prime}$ adalah suatu rainbow $k$-coloring dari $C_{n}$. Selanjutnya, misalkan $P$ adalah lintasan dari $u$ ke $v$ pada $C_{n}$. Maka $P$ adalah lintasan $u$-v geodesic di $C_{n}$, sehingga $P$ adalah rainbow path, sementara $u-v$ path lainnya di $C_{n}$ bukan rainbow path karena memiliki panjang $k+1$.

Tanpa mengurangi perumuman, misalkan $f^{\prime}\left(v_{k+1} v_{k+2}\right)=k$. Pandang titik-titik $v_{1}, v_{k+2}$ dan $v_{k+2}$. Karena lintasan $v_{1}-v_{k+1}$ geodesic $P: v_{1}, v_{2}, \cdots, v_{k+1}$ adalah rainbow path dan lintasan $v_{1}-v_{k+2}$ geodesic, $Q: v_{1}, v_{n}, \cdots v_{n-1}, v_{k+2}$ adalah rainbow path, maka beberapa sisi di $P$ dan $Q$ dapat diwarnai dengan warna $k$. Karena $v_{2}-v_{k+2}$ geodesic, $v_{2}, v_{3}, \cdots, v_{k+2}$ adalah rainbow path maka $f^{\prime}\left(v_{1} v_{2}\right)=k$. Dengan cara yang sama, $v_{n}-v_{k+1}$ geodesic, $v_{n}, v_{n-1}, v_{n-2} \cdots v_{k+1}$ sehingga $f^{\prime}\left(v_{n} v_{1}\right)=k$ diperoleh $f^{\prime}\left(v_{1} v_{2}\right)=f^{\prime}\left(v_{n} v_{1}\right)=k$. Ini berarti, tidak terdapat raibow $v_{2}-v_{n}$ path di 
$G$. Ini kontradiksi dengan $f^{\prime}$ adalah suatu rainbow $k$-coloring dari $C_{n}$. Jadi, haruslah $\operatorname{rc}\left(C_{n}\right)=\operatorname{src}\left(C_{n}\right)=k+1$.

Proposisi 2.3. [3] Untuk $n \geq 3$, bilangan rainbow connection dari graf roda $\left(W_{n}\right)$ adalah

$$
r c\left(W_{n}\right)=\left\{\begin{array}{l}
1, \text { untuk } n=3 \\
2, \quad \text { untuk } 4 \leq n \leq 6 \\
3, \quad \text { untuk } n \geq 7
\end{array}\right.
$$

Bukti. Misalkan $W_{n}$ terdiri dari $n$-cycle, $C_{n}:\left\{v_{1}, v_{2}, \cdots, v_{n}, v_{(n+1)}=v_{1}\right\}$ dan $v$ adalah titik lain yang terhubung pada setiap titik di $C_{n}$. Karena $W_{3} \simeq K_{4}$, maka berdasarkan Proposisi 2.1, diperoleh bahwa $r c\left(W_{3}\right)=1$. Misalkan $c(e)$ adalah pewarnaan pada suatu graf $G$. Untuk $4 \leq n \leq 6, W_{n}$ bukan merupakan graf lengkap, sehingga $r c\left(W_{n}\right) \geq 2$. Definisikan pewarnaan $c: E\left(W_{n}\right) \rightarrow\{1,2\}$ sebagai berikut.

$$
\begin{array}{r}
c\left(v_{i} v\right)=\left\{\begin{array}{l}
1, i \text { ganjil } \\
2, i \text { genap }
\end{array}\right. \\
c\left(v_{i} v_{i+1}\right)= \begin{cases}1, i \text { ganjil } \\
2, i \text { genap }\end{cases}
\end{array}
$$

Diperoleh bahwa $r c\left(W_{n}\right)=2$ untuk $4 \leq n \leq 6$.

Untuk $n \geq 7$ terdapat 3-pewarnaan $c: E\left(W_{n}\right) \rightarrow\{1,2,3\}$, yang didefinisikan oleh:

$$
\begin{aligned}
c\left(v_{i} v\right) & =\left\{\begin{array}{l}
1, i \text { ganjil } \\
2, i \text { genap }
\end{array}\right. \\
c(e) & =3, \text { untuk setiap } e \in E\left(C_{n}\right) .
\end{aligned}
$$

Diperoleh bahwa $\operatorname{rc}\left(W_{n}\right) \leq 3$.

Selanjutnya akan ditunjukkan bahwa $r c\left(W_{n}\right) \geq 3$. Karena $W_{n}$ bukan merupakan suatu graf lengkap, maka $r c\left(W_{n}\right) \geq 2$. Asumsikan sebaliknya $r c\left(W_{n}\right)=2$. Misalkan $c$ adalah 2-pewarnaan pada $W_{n}$, dan asumsikan $c\left(v_{1} v\right)=1$. Untuk setiap $i$ dengan $4 \leq i \leq n-2$, terdapat lintasan $v_{1}-v_{i}$ dengan panjang 2 pada graf $W_{n}$, sehingga $c\left(v_{i} v\right)=2$ untuk setiap $4 \leq i \leq n-2$. Karena $c\left(v_{4} v\right)=2$, maka $c\left(v_{n} v\right)=1$, demikian pula untuk $c\left(v_{3} v\right)=2$ saling berhadapan dengan $c\left(v_{(n-1)} v\right)=1$. Karena $c\left(v_{(n-1)} v\right)=1$ maka $c\left(v_{2} v\right)=2$, sehingga ditemukan dua sisi yang berdekatan dengan warna yang sama $c\left(v_{2} v\right)=2$ dan $c\left(v_{5} v\right)=2$, yang mengakibatkan lintasan $v_{2}-v_{5}$ bukan merupakan rainbow connection pada graf $W_{n}$. Karena itu, $r c\left(W_{n}\right)=3$ untuk $n \geq 7$.

Teorema berikut menyajikan bilangan strong rainbow connection untuk graf roda dan graf kubik.

Proposisi 2.4. [3] Bilangan strong rainbow connection dari graf roda adalah $\operatorname{src}\left(W_{n}\right)=\lceil n / 3\rceil$ dengan $n \geq 3$.

Bukti. Misalkan $W_{n}$ terdiri dari $n$ lingkaran, $C_{n}:\left\{v_{1}, v_{2}, \cdots, v_{n}, v_{n+1}=v_{1}\right\}$ dan $v$ adalah titik lain yang terhubung pada setiap titik lain di $C_{n}$. Karena $W_{3} \simeq K_{4}$, 
maka berdasarkan Proposisi 2.1, $\operatorname{src}\left(W_{3}\right)=1$. Untuk $4 \leq n \leq 6$, diperoleh bahwa $r c\left(W_{n}\right)=2$, sehingga berdasarkan Proposisi 2.1, jelas bahwa $\operatorname{src}\left(W_{n}\right)=2$. Maka $\operatorname{src}\left(W_{n}\right)=\lceil n / 3\rceil$ untuk $4 \leq n \leq 6$.

Selanjutnya untuk $n \geq 7$, terdapat $k$ bilangan bulat sedemikian sehingga $3 k-$ $2 \leq n \leq 3 k$. Pertama-tama akan ditunjukkan bahwa $\operatorname{src}\left(W_{n}\right) \geq k$. Asumsikan kontradiksi yaitu $\operatorname{src}\left(W_{n}\right) \leq k-1$. Misalkan $c$ adalah pewarnaan strong rainbow $(k-1)$ coloring dari $W_{n}$. Karena $d(v)=n>3(k-1)$, maka terdapat $S \subseteq V\left(C_{n}\right)$ dimana $|S|=4$ dan semua sisi di himpunan $u v \mid u \in S$ berwarna sama. Akibatnya, terdapat dua sisi $u^{\prime}-u^{\prime \prime} \in S$ dimana $d_{C_{n}}\left(u^{\prime}, u^{\prime \prime}\right) \geq 3$ dan $d_{W_{n}}\left(u^{\prime}, u^{\prime \prime}\right)=2$. Karena $u^{\prime}, v, u$ " hanya $u^{\prime}, u$ " geodesic di $W_{n}$, maka terdapat rainbow $u^{\prime}-u$ " yang bukan geodesic di $W_{n}$. Jadi $\operatorname{src}\left(W_{n}\right) \geq k$.

Selanjutnya akan ditunjukkan bahwa $\operatorname{src}\left(W_{n}\right) \leq k$. Definisikan pemetaan strong rainbow $k$ coloring $c: E\left(W_{n}\right) \rightarrow\{1,2, \cdots, k\}$ dari $W_{n}$ yaitu sebagai berikut.

$$
c(e)= \begin{cases}1, & \text { jika } e=v_{i} v_{i+1}, i \text { bilangan ganjil } \\ 2, & \text { jika } e=v_{i} v_{i+1}, i \text { bilangan genap } \\ j+1, & \text { jika } e=v_{i} v, i \in\{3 j+1,3 j+2,3 j+3 ;\} \\ & \text { untuk } 0 \leq j \leq k-1 .\end{cases}
$$

Dapat dilihat bahwa terdapat lintasan $u-v$ geodesic. Oleh karena itu, diperoleh $\operatorname{src}\left(W_{n}\right)=k=\lceil n / 3\rceil$ untuk $n \geq 7$.

Pada Gambar 1 diberikan ilustrasi bilangan strong rainbow connection graf roda dengan $n=7$.

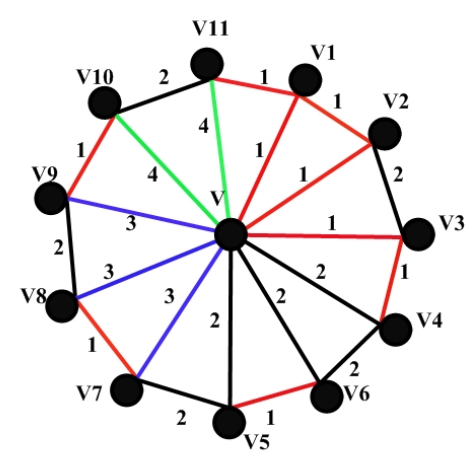

Gambar 1. Strong rainbow connection untuk graf roda

Pada kajian ini akan ditentukan bilangan rainbow connection dan bilangan strong rainbow connection dari graf kubik $C^{n}$ yang dapat direpresentasikan menjadi tepat dua lingkaran yang saling lepas (two disjoint cycle). Karena graf kubik tersebut memuat tepat dua lingkaran yang saling lepas maka banyak titik dari graf kubik $C^{n}$ adalah genap, yaitu $n=2 m$ untuk suatu bilangan asli $m \geq 3$. Jelas bahwa graf kubik adalah graf yang setiap titiknya berderajat tiga (3-reguler). Perhatikan dua graf 
lingkaran dalam $C_{m}^{d}$ dan graf lingkaran luar $C_{m}^{l}$ dengan masing-masing $m \geq 3$ titik. Misalkan himpunan titik lingkaran dalam adalah $V\left(C_{m}^{d}\right):=\left\{v_{1}, v_{2}, \cdots, v_{m} u_{m+1}=\right.$ $\left.v_{1}\right\}$ dan himpunan titik lingkaran luar adalah $V\left(C_{m}^{l}\right):=\left\{u_{1}, u_{2}, \cdots, u_{m} u_{m+1}=\right.$ $\left.u_{1}\right\}$. Jadi, jumlah titik setiap graf kubik adalah genap yaitu $\left|V\left(C^{n}\right)\right|=2 m$ untuk suatu bilangan asli $m \geq 3$. Teorema berikut memperlihatkan bilangan rainbow connection dan bilangan strong rainbow connection dari graf kubik $C^{n} \operatorname{dengan} n=$ $2 m$ titik.

Teorema 2.5. $\diamond$ Untuk $n \geq 4$, bilangan rainbow connection dan bilangan strong rainbow connection dari graf kubik $C^{n}$ yang direpresentasikan dengan dua buah graf lingkaran sehingga $n=2 m$ titik adalah

$$
r c\left(C^{n}\right)=\operatorname{src}\left(C^{n}\right)= \begin{cases}1, & \text { untuk } n=4 \\ m / 2+1, & \text { untuk } m \geq 3, m \text { genap } \\ \lceil m / 2\rceil, & \text { untuk } m \geq 3, m \text { ganjil } .\end{cases}
$$

Bukti. Akan dicari bilangan rainbow connection dan bilangan strong rainbow connection dari graf kubik. Perhatikan Gambar 2.

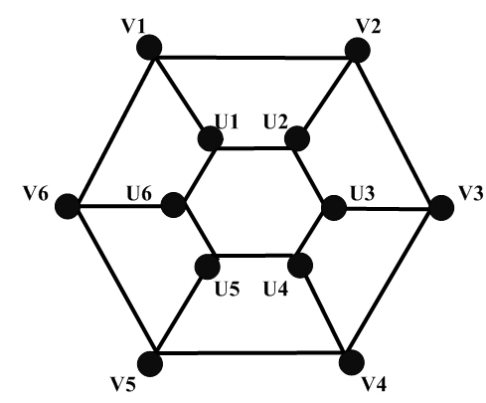

Gambar 2. Graf kubik dengan $n=12$ dan $m=6$

Dari Gambar 2, misalkan terdapat dua lingkaran dengan $m$ titik, lingkaran luar $C_{m}$ dengan $V\left(C_{m}\right)=\left\{v_{1}, v_{2}, \cdots, v_{6}\right\}$ dari graf kubik, dan lingkaran dalam $C_{m}^{\prime}$ dengan $V\left(C_{m}^{\prime}\right)=\left\{u_{1}, u_{2}, \cdots, u_{6}\right\}$ dan $E\left(C_{m}\right)=\left\{v_{i} v_{i+1}, u_{i} u_{i+1}\right\}$ untuk setiap $i$ di $G$ dengan $1 \leq i \leq m$. Karena $C^{4}=K_{4}$, berdasarkan Proposisi 2.1 maka $r c\left(C^{n}\right)=\operatorname{src}\left(C^{n}\right)=1$. Untuk $n \geq 6$, bilangan rainbow connection dan bilangan strong rainbow connection dari graf kubik adalah $\operatorname{rc}\left(C^{n}\right)=\operatorname{src}\left(C^{n}\right)=m / 2+1$ untuk $m$ genap dan $r c\left(C^{n}\right)=\operatorname{src}\left(C^{n}\right)=\lceil m / 2\rceil$ untuk $m$ ganjil. Pandang dua kasus berikut:

Kasus 1. $m$ adalah genap.

Misalkan $m=2 k$ untuk bilangan bulat $k \geq 2$ maka $\operatorname{src}\left(C^{n}\right) \geq \operatorname{rc}\left(C^{n}\right) \geq$ 
$\operatorname{diam}\left(C^{n}\right)=k+1$. Definisikan pewarnaan sisi $c(e)$ dari $C^{n}$ sebagai berikut.

$$
\begin{aligned}
c\left(v_{i} v_{i+1}\right) & = \begin{cases}i, & \text { untuk } 1 \leq i \leq k \\
i-k, & \text { untuk } k+1 \leq i \leq m .\end{cases} \\
c\left(u_{i} u_{i+1}\right) & = \begin{cases}i, & \text { untuk } 1 \leq i \leq k \\
i-k, & \text { untuk } k+1 \leq i \leq m .\end{cases} \\
c\left(v_{i} u_{i}\right) & =k+1, \text { untuk } 1 \leq i \leq m .
\end{aligned}
$$

Kasus 1. $m$ adalah ganjil.

Misalkan $m=2 k+1$ untuk bilangan bulat $k \geq 2$. Definisikan pewarnaan sisi $c(e)$ dari $C_{n}$ dengan

$$
\begin{aligned}
& c\left(v_{i} v_{i+1}\right)= \begin{cases}i, & \text { untuk } 1 \leq i \leq k+1 \\
i-k-1, & \text { untuk } k+2 \leq i \leq m .\end{cases} \\
& c\left(u_{i} u_{i+1}\right)= \begin{cases}i, & \text { untuk } 1 \leq i \leq k+1 \\
i-k-1, & \text { untuk } k+2 \leq i \leq m .\end{cases} \\
& c\left(v_{i} u_{i}\right)= \begin{cases}k+1, & \text { jika } e=v_{i} u_{i}, \quad i \in\{2 j, 2 j+1\}, \text { untuk setiap } j=0 \\
j, & \text { jika } e=v_{i} u_{i}, i \in\{2 j, 2 j+1\}, \text { untuk } 1 \leq j \leq k .\end{cases}
\end{aligned}
$$

Berdasarkan Kasus 1 dan Kasus 2 pada Proposisi 2.3, untuk $n$ genap dan $n$ ganjil sama halnya dengan $m$ genap dan $m$ ganjil yang terdiri dari dua buah lingkaran dalam dan lingkaran luar $m 1$ dan $m 2$. Setiap titik pada lingkaran dalam dan lingkaran luar dihubungkan oleh satu sisi $\left(v_{i} u_{i}\right)$, dan terdapat lintasan $u v$ yang bukan geodesic jika $r c\left(C^{n}\right)=\operatorname{src}\left(C^{n}\right)=k$ untuk $m$ genap. Jadi, haruslah $r c\left(C^{n}\right)=\operatorname{src}\left(C^{n}\right)=k+1$ untuk $m$ genap dan $m$ ganjil.

Pada Gambar 3 diberikan ilustrasi bilangan rainbow connection dan bilangan strong rainbow connection pada graf kubik $n=16$ dan $m=8$.

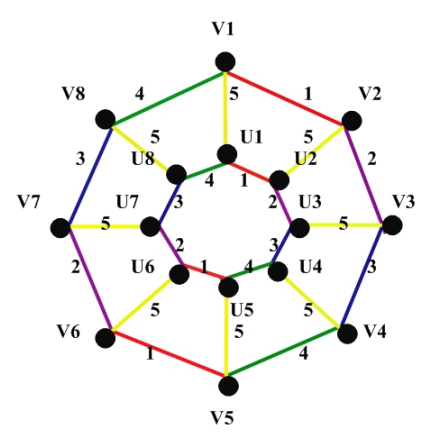

Gambar 3. Graf kubik dengan $n=16$ dan $m=8$

\section{Kesimpulan}

Pada tulisan ini telah diperoleh bilangan rainbow connection dan bilangan strong rainbow connection untuk graf roda dan graf kubik. 


\section{Ucapan Terima Kasih}

Penulis mengucapkan terima kasih kepada Bapak Prof. Dr. Syafrizal Sy, Dr. Muhafzan, Bapak Dr. Admi Nazra, Bapak Dr. Mahdhivan Syafwan, dan Ibu Dr. Lyra Yulianti yang telah memberikan masukan dan saran sehingga tulisan ini dapat diselesaikan dengan baik.

\section{Daftar Pustaka}

[1] Chartrand, G. dan P. Zhang, 2006. Introduction to Graph Theory, McGraw-Hill International Editions, Singapore.

[2] Syafrizal Sy, Gema Histamedika dan Lyra Yulianti, 2013. Rainbow Connection Numbers of fan and sun, Applied Mathematical Sciences 7: 3155 - 3159.

[3] Chartrand, G. dkk, 2008. Rainbow Connection in Graphs, Math. Bohem. 133 : $85-98$.

[4] Xveliang Li and Yuefang Sun, 2011. Rainbow Connection Number of Line Graphs, Ars Combin. 100 : $449-463$.

[5] Xveliang Li and Yuefang Sun, 2012. Rainbow Connection of Graphs, Springer Briefs in Mathematics, New York. 